\title{
A EUROPEAN FRAMEWORK FOR RECORDING AND SHARING DISASTER DAMAGE AND LOSS DATA
}

\author{
C. Corbane *, T. De Groeve, D. Ehrlich, K. Poljansek \\ European Commission, Joint Research Centre, Via Enrico Fermi 2749, ISPRA 21027 VA, Italy \\ Christina.corbane-clairotte@ext.jrc.ec.europa.eu \\ tom.de-groeve@jrc.ec.europa.eu \\ daniele.ehrlich@jrc.ec.europa.eu \\ karmen.poljansek@ext.jrc.ec.europa.eu \\ Commission IV, WG IV/7
}

KEY WORDS: Disasters, Damages, Human Losses, Economic Losses, Data Recording, Sendai Framework, Disaster Risk Reduction

\begin{abstract}
:
The recently adopted 'Sendai Framework for Action on Disaster Risk Reduction 2015-2030' sets the goals to reduce loss of life, livelihood and critical infrastructure through enhanced national planning and international cooperation. The new Framework is expected to enhance global, regional and national efforts for building resilience to disasters, across the entire disaster management cycle (prevention, preparedness, response and early recovery). Improved monitoring and accountability frameworks, relying on harmonized disaster loss data will be required for meeting the targets and for capturing the levels of progress across different scales of governance. To overcome the problems of heterogeneous disaster data and terminologies, guidelines for reporting disaster damage and losses in a structured manner will be necessary to help national and regional bodies compile this information. In the European Union, the Member States and the European Commission worked together on the establishment of guidelines for recording and sharing disaster damage and loss data as a first step towards the development of operational indicators to translate the Sendai Framework into action. This paper describes the progress to date in setting a common framework for recording disaster damage and loss data in the European Union and identifies the challenges ahead.
\end{abstract}

\section{INTRODUCTION}

The Sendai Framework for Action on Disaster Risk Reduction (DRR) 2015-203aims at substantially reducing disaster losses in lives, and in the social, economic, and environmental assets of communities and countries. ${ }^{1}$ The demand for consistent, reliable, detailed and accessible data on disaster impacts is one of the key challenges of the new Framework. Systematic collection of disaster loss data has long been identified as an essential asset for the success of disaster risk reduction at global, regional and national levels (Guha-Sapir and Lechat, 1986; Gall et al., 2009; Mitchell et al., 2014).

In the European Union, the relevance of disaster loss data for evidence-based disaster risk reduction policies has been recognized and translated in two main policy documents: 1) the new European Union (EU) legislation on Civil Protection ${ }^{2}$ which includes key actions related to DRR: i) the development of national risk assessments, ii) the refinement of risk management planning and iii) the provision of guidelines and methods of risk assessment and mapping to ensure comparability among the Member States. 2) The EU Council Conclusions $^{3}$ on risk management capability which stressed the

1 Sendai Framework for Disaster Risk Reduction 2015-2030. http://www.wcdrr.org/uploads/Sendai_Framework_for_Disaster_Ris k_Reduction_2015-2030.pdf

2 Decision No 1313/2013/EU of the European Parliament and of the Council of 17 December 2013 on a Union Civil Protection Mechanism, OJL(347), 20.12.2013

3 Council Conclusions on risk management capability, 13375/14 of 24 September 2014 importance of disaster loss data and invited the European Commission (EC) to take actions to encourage the EU Member States to develop systems, models or methodologies for collecting and exchanging data on ways to assess the economic impact of disasters on an all-hazard basis.

To identify the gaps and challenges for recording loss data in Europe and promote the opportunities for policy making based on evidence, the Directorate General Joint Research Centre was tasked in 2013 to establish an expert working group with participants from EU Member States to report on the current state of the art in Europe and recommend best practices and guidelines. Sixteen Member States participated to five meetings organized between 2013 and 2015. The EU working group benefited also from an exchange of information with the United Nations Office for DRR (UNISDR) and an international working group addressing loss data affiliated with the Integrated Research on Disaster Risk (IRDR), as well as various academic and scientific institutions.

Taking stock of existing practices in disaster loss recording (at national and international levels), the EU working group prepared a roadmap towards the establishment of an operational common framework for recording disaster damage and loss data in the European Union. This paper aims at summarizing the progress achieved in this direction starting from the analysis of the uses of loss data (section 2), followed by an overview of the current practices in recording disaster loss data in EU Member States (section 3), until the recent development of guidelines for recording and sharing disaster damage and loss data (section 4). 


\section{THE APPLICATION AREAS OF DISASTER LOSS DATA AND THE ISSUES OF SCALE AND SCOPE}

Disaster loss data are useful for a range of applications related to disaster management. Recording disaster loss data is the mechanism that links the science of disaster management to policy making for reducing disaster risks. De Groeve et al. ( 2013, 2014) developed a conceptual framework for loss data recording that comprises four main application areas : loss compensation, accounting, forensic analysis and disaster risk modelling. The four areas differ in granularity (precision) and scope (coverage) requirements. A theoretical model allows to evaluate existing databases for fitness for use for particular applications, or to understand the granularity and scope - and the related investment - to develop new databases.

\subsection{The four applications areas of disaster loss data}

\subsubsection{Disaster loss compensation}

A fair and efficient solidarity mechanism and effective insurance markets are complementary approaches to recover from disasters. Most disaster loss databases in Europe are based on a collection of claims used in these compensation mechanisms. The drivers for loss data recording are mainly linked to public national compensation schemes (e.g. Belgium, Croatia, France, Slovenia, Spain, Sweden) as well as two important governance mechanisms: Public-Public Partnerships (PuP) and Public Private Partnerships (PPP). In France, Mission Risques Naturels (MRN) provides evidence of the efficiency of PuP and PPP mechanisms for establishing and maintaining national disaster loss databases. Private and public partnerships that rely on cost-sharing allow developing openaccess models and pilot innovative loss data management mechanisms.

\subsubsection{Disaster loss accounting}

Loss accounting is the principal motivation for recording the impact of hazards and aims to document the trends in time. High quality loss data with a good temporal and spatial resolution may be used to establish historical baseline for monitoring the level of impact on a community or country. In fact, disaster loss accounting is being considered as backbone for setting the baseline (i.e. a decade of national observations on mortality and economic loss data) and measuring the progress towards the agreed targets within the post 2015 framework for disaster risk reduction. While not all countries have national disaster loss databases, the adoption of these targets and indicators based on national observations will represent a strong incentive for systematically recording loss data.

\subsubsection{Disaster forensics}

Fine scale disaster loss data recording generates crucial and unique evidence for disaster forensics. This allows identifying loss drivers by measuring the relative contribution of exposure, vulnerability, coping capacity, mitigation and response to the disaster, that provides the lessons learnt to improve disaster management. Disaster forensics collected for individual events is critical evidence for evaluating the effectiveness of specific disaster prevention measures, and disaster prevention policy as a whole. Disaster forensic studies rely largely on loss data. Tools are available, such as the Damage and Loss Assessment (DaLA) methodology developed by the Economic Commission for Latin America and the Caribbean (ECLAC) (Global Facility for Disaster Reduction and Recovery (GFDRR), 2010). The DaLA methodology builds on loss data collection, recording and analysis with the purpose of identifying root causes of disasters and determining recovery and reconstruction needs. Over the last 40 years, the ECLAC has conducted specific loss assessments in a systematic manner generating historical evidence of the social and economic consequences these events have on the countries.

\subsubsection{Disaster risk modelling}

Disaster models aim to address the questions such as what can go wrong? How likely is it that this will happen? If it does, what are the consequences? (Kaplan and Garrick, 1981; Kirchsteiger, 1999). The questions may be addressed using a combination of two modelling approaches: probabilistic and deterministic modelling. Deterministic modelling aims to identify what can go wrong and how bad based on a point event and is typically geographically constraint. It is used to determine shortcomings in protection of natural events at local to city level. Deterministic models are simple to implement and the message is easy to convey. Probabilistic models on the other hand aim to inform on future losses at the national and global levels.

The worst disasters have not happened yet. This is a key message from UNISDR's Global Risk Assessment 2013. Losses of future disasters are estimated through probabilistic risk models. These require accurate loss data for calibrating and validating models, to infer vulnerabilities, loss exceedance curves and fragility (or damage) curves. Disaster risk model typically comprise three main modules: hazard, vulnerability and loss. The latter combines the hazard module and the exposure module to calculate different risk metrics, such as annual expected loss (AEL) and probable maximum losses (PML) for various return periods. The AEL and PML are used to compliment historical analysis and are particularly useful for decision makers in assessing the probability of losses and the maximum loss that can result from major future events. Additionally, these assessments can also incorporate climate change scenarios to help the governments in developing forward-looking adaptation strategies.

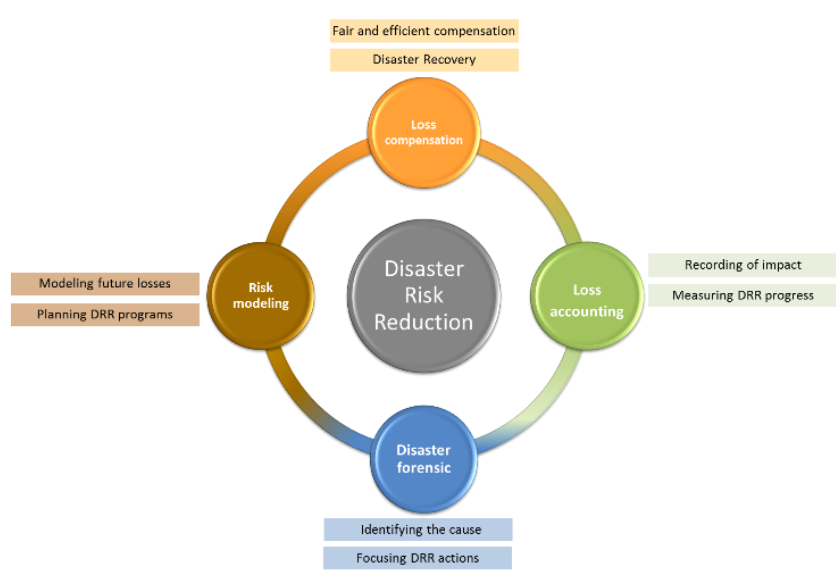

Figure 1. The four application areas of disaster loss data and their respective objectives

\subsection{The granularity and scope of disaster loss data}

The available data portraying past disasters show that the granularity and the scope of disaster losses are two important dimensions of loss data that allow the distinction between different data collection techniques and disaster loss databases. The granularity expresses the measurement scale. It provides an indication on the detail of loss data recording. Whereas scope refers to the geographical scale (Zhang et al., 2014): asset, 
municipality, regional, national and global level. Disaster outcomes may affect more than one asset and more than one municipality or even region. Mass disasters typically extend beyond municipalities and regions. Most of the international databases do not record disasters at local or municipal level, failing therefore to provide an accurate assessment of global losses.

The link between granularity and scope is important. The information can be collected at the asset level, and be very precise. The data can then be aggregated at the next geographical level (i.e., municipality) and further on at the regional and national level. The ideal database has national scope and local scale. This is the case, for example, when the information is collected based on census information, or when citizens report themselves, like for insurance claims (although the latter's completeness depends on insurance penetration rates). In these databases, the property's (or asset) physical location, size and value are reported. The loss is a fraction of the total value. That information will remain accurate even if in aggregated form.
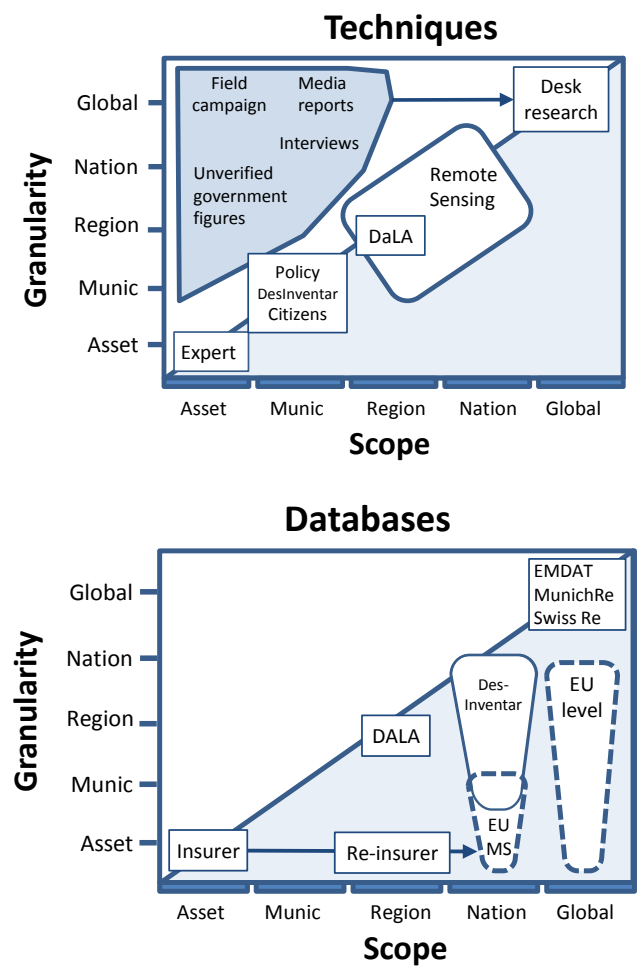

Figure 2. Scatter plots illustrating scope and granularity of information for loss data collection techniques and databases (modified from De Groeve et al., 2013). ${ }^{4}$

Figure 2 shows a scatter plot using horizontal axes as the scope with the 5 geographical levels and the vertical axes as the granularity with the 5 geographical levels. Moving from the asset level on the vertical axes up to the global level, the information may become less precise or more uncertain. In fact,

${ }^{4}$ EM-DAT (CRED), Munich RE NatCatSERVICE and Swiss RE Sigma CatNet Service are a global databases at national resolution. DesInventar (UNISDR) is a depository of national databases collected on subnational/local level. loss data are often derived from media reports, unverified government figures, often provided only at regional or national level, that lack evidence-based measurements. These estimates are quickly generated as preliminary estimates of damage and often remain the only source of information and thus enter the international loss databases.

In reality, loss data are seldom collected at the assets level (e.g. damage level and reconstruction cost). Most of the time the data are estimated based on rapid surveys by professionals that provide estimates at the municipality levels (e.g. $10 \%$ of houses destroyed, 30\% damaged). In mass disasters, when government functions are disrupted, and the mandated institutions are impaired, then the information may collected by external actors on an ad hoc basis without necessarily reporting at the municipality level (e.g. DaLA methodology). The data may even be provided by government institutions at the regional or national level without a thorough systematic accounting.

The information needs for the four application areas are overlapping but differing in terms of granularity and scope. The latter ranges from detailed loss at asset level (e.g. for individual compensation claims), through aggregate statistics or estimates at municipality, regional and national levels (e.g. reporting to the Sendai Framework), and all the way to globally aggregated trends and statistics (e.g. used in climate change discussions). To be cost effective, the granularity of recording losses and the scope of loss databases should be optimized based on the requirements of the application area.

\section{STATUS OF LOSS DATA RECORDING IN THE EU}

On the basis of the conceptual framework for loss data recording developed in De Groeve et al., 2013 (section 2) a state of the art analysis on recording disaster loss data in $15 \mathrm{EU}$ Member States was carried out in 2014 (De Groeve et al., 2014). The collected information was structured according to the four distinct phases of the loss data analysis framework:

- The national drivers for loss data which correspond to the purpose and the legal basis for loss data collection and recording.

- The methodology of collection which identifies the timing, the means and the actors. It is related to the purpose of the loss database.

- The methodology of recording which explains how data should be stored once field data have been collected. The data need to be organised into a manageable database of pre-defined formats and fields ready to be analysed efficiently. This involves transcribing data into a systematic format, entering the information obtained from each field assessment group or organization and organising it into one overall structured database.

- The model of disaster loss database which determines the logical structure of the loss database, and in which format data can be stored, organized and manipulated.

\subsection{Lessons learned}

The overview of the current practices in recording disaster loss data in EU Member States showed that the methodologies implemented in each country are appropriate for their purpose. However, to make the databases compatible with requirements for sharing data among Member States and with international organisations they all would require adjustments. The loss recording practices also would need to be strengthened to make 
the data useful at national level beyond narrowly defined objectives, e.g. for prevention policy and risk assessment.

The main gaps and challenges for harmonised loss data recording with the EU were as follows: i) the lack of guidelines and standards for loss data collection and recording, which prevent the aggregation of loss data et EU and global levels and ii) the absence of national legal frameworks and strong mandates, essential for the establishment of country-wide and multi-hazard loss databases.

\subsection{Main recommendations}

Given the state of the art in the EU Member States and the perceived weaknesses and gaps, some options to address these shortcomings in a realistic way are proposed. They underscore the areas in which collaboration between Member States is desired, and prefigure the expected benefits be for Member States and the EU as a whole:

- The role and utility of loss data should be discussed across government departments, including emergency management, urban planning, and government budget and across all government scales and participative governance fora (local to national). High-level requirements should be informed by public and private needs across sectors. Implementation might be embedded in a Public-Public Partnership (PUP) and/or Public Private Partnership (PPP) to ensure participation and ownership of all stakeholders.

- Loss data should be recorded in advanced (distributed) IT systems, implementing an appropriate data model (linked to or integrated with other government databases) and supporting user-friendly data visualization and sharing options for a wide range of users.

- Summary or aggregate statistics should be shared using an open data policy in a common data standard to support trans-boundary and international risk reduction processes, including the Sendai Framework for DRR.

- Minimum requirements for a data-sharing standard aligned with current practices are desirable for guiding the collection and sharing of sound comparable and interoperable data on disaster losses in an open data policy.

\section{EU GUIDANCE FOR RECORDING AND SHARING DISASTER DAMAGE AND LOSS DATA}

Building on the findings and the recommendations of the two previous studies (De Groeve et al., 2013; 2014), the European Commission together with the Member States worked on the establishment of guidelines for recording and sharing disaster damage and loss data (EU expert working group on disaster damage and loss data, 2015).

\subsection{Scope of the guidelines}

The proposed guidelines are based on a targeted consultation with experts from Member States with the aim of supporting and enhancing the different strands of disaster prevention such as risk assessment and risk management. Their purpose is to help Member States in improving the coherence and completeness of the national disaster damage and loss data recording process, necessary for supporting evidence-based disaster risk management policies and actions. They propose essential elements of an assessment methodology for recording damage and loss data and recommend simplified aggregate figures for sharing the data following a common data exchange format. The proposed common framework for damage and loss data recording directly supports reporting on indicators for global disaster risk reduction targets, envisaged as part of the EU commitment to the post-2015 Sustainable Development Goals and to the Sendai Framework for Disaster Risk Reduction.

The guidelines outline the elements of the disaster damage and loss data model that are important and that should be reflected in national data models. The design requirements of the databases depend on the application area. For damage and loss data-sharing standards a minimum set of damage and loss indicators are proposed. To overcome the complexity of the loss recording process within the national contexts, the guidelines also recommend simplified aggregate figures following a common data exchange format.

\subsection{Model of disaster loss databases}

A data model is the description of the classes together with the definition of the data fields as well as relationships among the classes. It determines the logical structure of a database, and in which format data can be stored, organized and manipulated. The guidelines propose a conceptual model for damage and loss data recording inspired from existing national loss databases and widely used tools for generating disaster inventories (e.g. DesInventar). The conceptual model attempts to comply with the targets of the Sendai Framework for Disaster Risk Reduction and the indicators under negotiation that will be used for measuring global progress.

The conceptual model can be adapted to the national contexts to take into account local requirements, including factors such as language, staff management, and access and security. The design requirements of loss databases depend also on the application area (i.e. loss compensation, loss accounting, forensic analysis and disaster risk modelling). The information needs for the four application areas are overlapping, even if the forensic and modelling applications require information at higher detail.

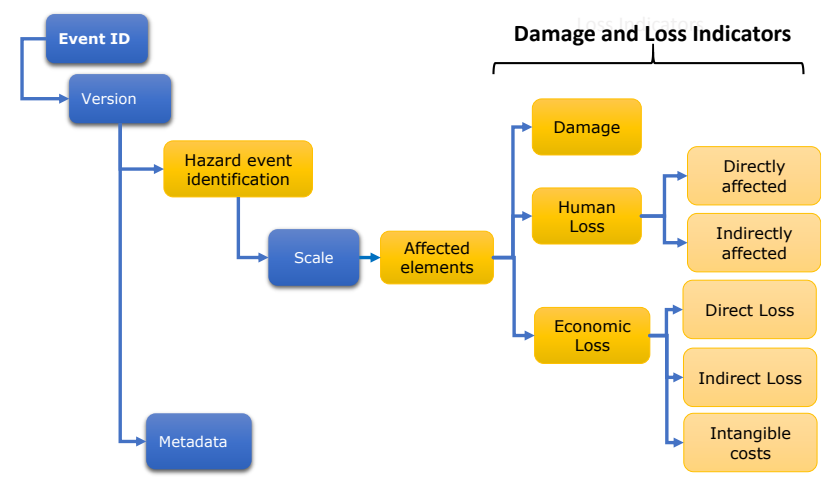

Figure 3. Conceptual data model for damage and loss data recording. For each field of the damage and loss indicators (damage, human and economic losses), it is recommended to assign an uncertainty value.

The conceptual model (Figure 3) starts from a disaster event, identified unambiguously (likely with an event identifier). There may be several versions of loss records associated to the event, 
e.g. through updates and corrections (where data becomes available), temporal versions to capture event dynamics (evolution of losses), or estimates of different organisations. For each version, three sets of indicators of disaster losses (hazard event identification, the affected elements, the damage and the loss indicators) can be recorded after the occurrence of a disaster as well as metadata and quality assurance information. Metadata contains information such as entry date, author, validation status and information on the methodologies used for assessing the damage and estimating the human and economic losses. The affected element may correspond to a house, a municipality, a province or a country, etc. A Member State may choose to record damage and loss data at given scale and then aggregate at coarser scales (e.g. the municipality level may be obtained by aggregating losses recorded at asset level or it may be assessed directly). The scale at which damage and loss data are recorded influences directly the quality of aggregated losses. Collecting data at the asset level will decrease uncertainty of loss indicators and increase the transparency of economic losses caused by a disaster.

\subsection{Indicators of the disaster damage and loss database}

The guidelines define three sets of indicators of disaster losses (hazard event identification, the affected elements, the damage and the loss indicators) corresponding to the type of information on the disaster and its impacts that needs to be recorded in a disaster loss database as well as the recommended classifications and standards to define them. For each indicator, the guidelines define a set of minimum requirements necessary for a loss data-sharing standard:

\subsubsection{Hazard event identification}

A disaster damage and loss database is an event-based database, i.e. loss data are related to a specific hazard event which should be uniquely identified (spatially and temporally), classified to provide basic summary statistics (e.g., aggregation by peril type, year), and recorded by severity level to relate to the probability of occurrence for calculation of average annual losses. Hazard event identification allows attributing the losses to a peril. The attribution assumes a peril classification. The INSPIRE natural hazard category defined in the INPIRE data specifications for Natural Risk Zones (INSPIRE Thematic Working Group Natural Risk Zones, 2013) is recommended as standard for the classification of natural hazards. It is feasibly extensible with the peril classification of the IRDR DATA working group (IRDR DATA working group, 2014)

\subsubsection{Affected elements}

The affected element can be a human or a physical asset (i.e. building). The type of the affected element defines the associated loss indicators as well as the methodology of collection. The set of the affected elements is a subset of all exposed elements (elements at risk) located in the affected area. The data specifications for the affected elements are described under the "Exposed Element" feature in the INSPIRE Natural Risk Zones Data Specification. Pre-event characteristics of the affected elements allow even more profound analysis in all application fields, such as loss accounting by spatial unit, sectors or loss ownership; disaster forensic expertise of lessons learnt based on hazard dependent characteristics; and exact location and vulnerability of the affected elements for risk modelling. It is not required to record information on the affected elements for the purpose of data-sharing. However, efforts in addressing more specific, numerous and detailed fields are strongly encouraged for linking loss accounting to other application with local benefit (such as disaster forensics and risk modelling).

\subsubsection{Damage and loss indicators}

Damage and loss indicators are at the core of the disaster loss database. They comprise, damage, human and economic losses. They describe the level of damage on individual assets or on a number of damaged/destroyed assets covering several dimensions to thoroughly record the impact of the disasters. The degree of detail of damage depends on the availability of quantitative information in the area affected. Therefore the damage and loss indicator is not only a name of data field with the value and the physical unit but it is also accompanied with metadata including the time of recording/updating, the source and uncertainty as well as information on the assessment methodology. The unit should be standardized: for example, the unit for affected population should be persons. Data in other units (families, households) should be converted to number of persons. Definitions of the fields, the format of their codified value should follow standard definitions to provide comparability and consistency. The guidelines propose the following definitions for human losses, for damages and for economic losses:

- Human losses include: i) directly affected people, which are a subset of exposed people, that suffered either impacts on their livelihood immediately after the disaster or on their physical integrity; ii) indirectly affected people which correspond to people in the affected country that suffered indirect effects of the disaster and can be within or outside the affected area, iii) deaths which correspond to the number of people who died during the disaster, or some time after, as a direct result of the disaster and iv) missing which correspond to the number of persons whose whereabouts since the disaster are unknown. It includes people presumed dead without physical evidence.

- Damage indicators correspond to the total or partial destruction of physical assets existing in the affected are. They represent a summary of the damages in the cases where aggregates are generated. Their intention is to provide a minimum set of physical damage indicators in the form of a set of aggregated figures at spatial units above the asset level (i.e. municipality, region, country, etc.). Whenever the damage data collection does not occur at asset level, these indicators will allow to a large extent the validation and calibration of economic loss assessments and are useful in many ways as part of risk assessment and disaster forensic processes. They also ensure computability with the global targets for disaster risk reduction set in Sendai Framework and with the United Nations loss data collection initiative, based on DesInventar V10.0 (2015) ${ }^{5}$. They include the following minimum set of fields: houses destroyed, houses damaged, education centres and health facilities.

- Economic loss indicators represent market-based negative economic impact of a disaster. They include: i) direct losses, which are the monetary value of physical

\footnotetext{
${ }^{5}$ http://www.desinventar.org.
} 
damage to capital and tangible wealth assets. Direct losses may be also measured in terms of flows of foregone production; ii) indirect losses include lower output from damaged or destroyed assets and infrastructure and loss of earnings due to damage to transport infrastructure such as roads and ports, including business interruption. Indirect loss may also include costs such as those associated with the use of more expensive inputs following the destruction of cheaper sources of supply and iii) intangible costs which accrue to assets without an obvious market price and are therefore difficult to depict in monetary terms (e.g. environmental losses).

For the purpose of the loss data-sharing, only summary or aggregated statistics are required. Besides, only direct losses are recommended to be reported as minimum requirements so to ensure computability with the global targets for disaster risk reduction set in the Sendai Framework. To determine the overall amount of disaster impacts, direct losses for all affected sectors must be included, avoiding possible gaps or double accounting. It is recommended to define the type of the owner (individuals, business, government, non-governmental organizations). This allows for providing statistics on losses in the public sector, the industry sector, private citizens and so on. Separate from the owner type of the building, the losses of a particular building are typically borne partially by the insurance industry, partially by the owner and partially by public funds (e.g. disaster compensation funds). The loss owner, those that bears the losses (individuals, business, government, nongovernmental organizations and insurance companies) should be recorded. In case not all losses are recorded (e.g. only insured losses), it is recommended to develop a method for estimating the total losses across all loss-bearing entities (e.g. applying a coefficient factor on insured losses).

$\begin{array}{lc}\text { Hazard event identification } & \text { Minimum Requirement } \\ \text { Geographical information } & \text { Subnational level } \\ \text { Temporal information } & \mathrm{X} \\ \text { Hazard event classification } & \mathrm{X} \\ \text { Event type specific attributes } & \\ \text { Hazard event identification number } & \mathrm{X} \\ \text { Human loss indicators } & \mathrm{X} \\ \text { Directly affected } & \\ \text { Indirectly affected } & \mathrm{X} \\ \text { Deaths } & \mathrm{X} \\ \text { Missing } & \text { Total number } \\ \text { Damage Indicators } & \text { Total number } \\ \text { Houses destroyed } & \text { Total number } \\ \text { Houses damaged } & \text { Total number } \\ \text { Education centres } & \\ \text { Health facilities } & \mathrm{X} \\ \text { Economic loss indicators } & \\ \text { Direct loss } & \\ \text { Indirect loss } & \\ \text { Intangible costs } & \end{array}$

Table 1 . The primary indicators of the disaster damage and loss database and the minimum requirements for loss-data sharing

Table 1 summarizes the primary minimum indicators of the disaster damage and loss database. Extensive information on each of these fields can be found in De Groeve et al., (2013, 2014) and in the Guidance for Recording and Sharing Disaster Damage and Loss Data (2015). As damage and loss recording improves, expansion of databases to include more detailed indicators as refinements is highly desirable in order to provide a more comprehensive view of the socio-economic impacts of disasters.

\section{CONCLUSIONS AND WAY FORWARD}

This paper presented the different building blocks of the European framework for recording and sharing disaster damage and loss data. The framework aims at supporting Member States in their choice of implementation of disaster damage and loss databases while giving them enough freedom to decide which application areas are of their interest. For the loss recording process to be successful, the practices would need to be strengthened to make the data useful at national level beyond narrowly defined objectives (e.g. for prevention policy and risk assessment).

The proposed framework is currently being implemented and tested in an operational setting with the Member States' voluntary contribution (Italy, Sweden, Spain, Austria, etc.). The sample case studies involve different type of hazards (e.g. floods, droughts, landslides etc.) allowing to test the practicability of the proposed frameworks and to identify areas of improvement.

Ultimately, the European framework for recording and sharing disaster damage and loss data will contribute to improving accountability, transparency and governance which are the key principles of the new Sendai Framework. This will be achieved through the implementation of the proposed non-binding guidelines which encourage the collection and sharing of disaster damage and loss data in an open data policy. Once approved and endorsed by EU Member States, the common framework for recording disaster damage and loss data will be part of the European contribution to the development of operational indicators to translate the Sendai Framework into action.

\section{REFERENCES}

De Groeve, T., Poljansek, K., Ehrlich, D., 2013. Recording Disaster Losses: Recommendations for a European approach. Report by the Joint Research Centre of the European Commission- EUR 26111.

De Groeve, T., Poljansek, K., Ehrlich, D., Corbane, C., 2014. Current Status and Best Practices for Disaster Loss Data recording in EU Member States: A comprehensive overview of current practice in the EU Member States. Report by Joint Research Centre of the European Commission, EUR 26879.

EU expert working group on disaster damage and loss data, 2015. Guidance for Recording and Sharing Disaster Damage and Loss Data- Towards the development of operational indicators to translate the Sendai Framework into action, Report by the European Commission Joint Research Centre -EUR 27192.

Gall, M., Borden, K.A., Cutter, S.L., 2009. When Do Losses Count? Bulletin of the American Meteorological Society, 90 (6), 799-809.

Global Facility for Disaster Reduction and Recovery (GFDRR), 2010. Damage, Loss and Needs Assessment. Guidance Notes. Vol. 1-3. The World Bank, Washington.

Guha-Sapir, D., Lechat, M.F., 1986. The Impact of Natural Disasters: A Brief Analysis of Characteristics and Trends. Prehospital Disaster Med. 2, 221-223. 
INSPIRE Thematic Working Group Natural Risk Zones, 2013. D2.8.III.12 INSPIRE Data Specification on Natural Risk Zones - Technical Guidelines-, D2.8.III.12_v3.0.

IRDR DATA working group, 2014. Peril Classification and Hazard Glossary. DATA Project Report No. 1. http://www.preventionweb.net/english/professional/publications /v.php?id=36979.

Kaplan, S., Garrick, B.J., 1981. On The Quantitative Definition of Risk. Risk Analysis, 1 (1), 11-27.

Kirchsteiger, C., 1999. On the use of probabilistic and deterministic methods in risk analysis. Journal of Loss Prevention in the Process Industries 12 (5), 399 - 419.

Mitchell, T., Guha-Sapir, D., Hall, J., Lovell, E., Muir-Wood, R., Norris, A., Scott, L., Wallemacq, P., 2014. Setting, Measuring and Monitoring Targets for Disaster Risk Reduction: Recommendations for post-2015 international policy frameworks. Overseas Development Institute, London, 69 p.

Zhang, J., Atkinson, P., Goodchild, M., 2014. Scale in Spatial Information and Analysis. CRC Press, Boca Raton, Florida, USA, $367 \mathrm{p}$. 